\title{
COMENTARIO A LA STC 140/2016, DE 21 DE JULIO, SOBRE TASAS JUDICIALES
}

\author{
David VALLESPín PÉREZ \\ Catedrático de Derecho Procesal \\ Facultad de Derecho \\ de la Universitat de Barcelona \\ dvallespin@ub.edu
}

\section{ANTECEDENTES}

Como es sabido, el día 19 de febrero de 2013 tuvo entrada un escrito en el Registro General del Tribunal Constitucional, presentado en representación de ciento nueve diputados del Grupo Parlamentario Socialista en el Congreso, por el que se interpuso recurso de inconstitucionalidad contra determinados preceptos de la Ley 10/2012, de 20 de noviembre, por la que se regularon determinadas tasas en el ámbito de la Administración de Justicia y del Instituto Nacional de Toxicología y Ciencias Forenses ${ }^{1}$. En con-

\footnotetext{
${ }^{1}$ Para un completo estudio doctrinal acerca de la polémica sobre el concepto y cuantía de las tasas judiciales, y, en particular, sobre la constitucionalidad o no de la Ley 10/2012, vid., por todos, J. M. Asencio Mellado, «La inconstitucionalidad de la Ley de Tasas 10/2012, de 20 de noviembre», Diario La Ley, núm. 8115 (2013); J. Banacloche PalaO, «El derecho de los ciudadanos a acceder a la justicia: tasa judicial y tutela efectiva», en J. E. SORIANO GARCía (dir.) y M. Estepa MonTERo (coord.), Por el Derecho y la libertad, vol. I, Madrid, Iustel, 2014, pp. 343-369; J. L. BeLtrán AguiRRE, «Las nuevas tasas judiciales y los derechos fundamentales a la tutela judicial efectiva y a la igualdad ante la ley», Revista Aranzadi Doctrinal, núm. 10 (2013), pp. 33-46; R. BONACHERA VILLEGAS, «La tasa judicial en el ámbito del proceso contencioso-administrativo de la jurisdicción», Revista Práctica de Tribunales, núm. 102 (2013), pp. 6-15; G. Doménech Pascual, «Las tasas judiciales a juicio. Comentario crítico de la Sentencia del Tribunal Constitucional 140/2016, de 21 de julio», InDret. Revista para el análisis del Derecho, núm. 1 (2017); V. GIMENO SENDRA, «Acerca de la constitucionalidad de la Ley de Tasas Judiciales», Revista General de Derecho Procesal, núm. 29 (2013); íD., «Tasas judiciales y financiación de la justicia», Revista General de Derecho Procesal, núm. 39 (2016); ÍD., «La retroactividad de la STC 140/2016 sobre las tasas judiciales», Revista General de Derecho Procesal, núm. 40 (2016); A. JimÉnEz Díaz, «Los efectos de la Sentencia del Tribunal Constitucional sobre las tasas judiciales: situaciones transitorias y posibilidad de devolución de lo ingresado», Diario La Ley, núm. 8834 (2016); V. MAGRO SERVET, «Análisis sobre la viabilidad constitucional de la Ley 10/2012, de 20 de noviembre, de Tasas Judiciales», Diario La Ley, núm. 7971 (2012); íD., «Sobre la polémica de las tasas judiciales», Elderecho.com, julio de 2013, pp. 1 y ss.; A. J. Pérez-Cruz Martín, «La Ley 10/2012, de 20 de noviembre, por la que se regulan determinadas tasas en el ámbito de la Administración de Justicia y del
} 
creto, los preceptos sometidos a la valoración del Tribunal Constitucional fueron sus arts. 1 (ámbito de aplicación de la tasa), 2 (hecho imponible), 3 (sujeto pasivo), 5 (devengo), 6 (base imponible), 7 (determinación de la cuota tributaria) y 11 (vinculación de la tasa al sistema de justicia gratuita).

La fundamentación jurídico-material del recurso se articula en cuatro motivos, a los cuales precede una consideración de carácter general. Según ésta, la Ley 10/2012 supone en su conjunto la vulneración de diversos preceptos constitucionales, singularmente del derecho a la tutela judicial efectiva del art. 24.1 CE, «algo no imputable aisladamente a concretos preceptos legales, sino al efecto combinado de los mismos, en tanto que sistema cerrado de recaudación tributaria que limita de forma irrazonable y discriminatoria el ejercicio de derechos fundamentales, incorporando soluciones frontalmente contrarias a principios establecidos en el texto constitucional».

El primer motivo del recurso, que se titula «Legitimidad del establecimiento de un sistema de tasas en el servicio público de justicia y límites constitucionales», se presenta dividido en dos grandes apartados. En el primero, referido al «acceso al juez y al Estado de Derecho», los recurrentes defienden la importancia que tiene en nuestra cultura jurídica la atribución al Estado-poder judicial de la función de heterocomposición de los conflictos jurídicos, en vez de optar por el fomento de mecanismos alternativos a la jurisdicción como el arbitraje y la mediación, como sucede en los países anglosajones. Como consecuencia de ello denuncian, precisamente, que la falta de acceso a la jurisdicción produce, además de una vulneración del derecho fundamental a la tutela judicial efectiva (art. 24.1 CE), una «quiebra objetiva del Estado de Derecho, que la Constitución incorpora como uno de sus fundamentos (art. 1.1 CE)». La demanda reconoce que no cabe cuestionar que la financiación de los servicios públicos se lleve a cabo no solamente a través de la vía más habitual de los impuestos, sino también mediante otras figuras tributarias como la tasa, pero siempre y cuando ello no violente ninguna previsión constitucional.

Instituto Nacional de Toxicología y Ciencias Forenses: dudas sobre su inconstitucionalidad», Revista Práctica de Tribunales, núm. 102 (2012), pp. 14-30; E. SÁnchez Álvarez, «Un enjuiciamiento constitucional del actual modelo de tasas judiciales. Motivos para su inconstitucionalidad a pesar de las sucesivas atemperaciones legislativas. Propuestas de futuro», Revista CEFLegal, núm. 181 (2016), pp. 111-150; íD., «Límites constitucionales a la inserción de las tasas judiciales autonómicas. Comentario crítico a la STC 71/2014, de 6 de mayo», Estudios Deusto, vol. 64, núm. 1 (2016), pp. 377-394, e íd., A. SEMPERE NAVARRO, «Las tasas judiciales en el orden social», Revista Aranzadi Doctrinal, núm. 1 (2013), pp. 49-58. 
Se afirma por los recurrentes que la Ley 10/2012 desprecia las cautelas adoptadas en su día tanto por la Ley 25/1986, de Supresión de las Tasas Judiciales, que resolvió abolir éstas², como por la posterior Ley 53/2002, de Medidas Fiscales, Administrativas y del Orden Social, cuyo art. 35 reguló una tasa por el ejercicio de la potestad jurisdiccional en los órdenes civil y contencioso-administrativo, pero que supuso una reintroducción limitada ${ }^{3}$. En cambio, según los recurrentes, la Ley

${ }^{2}$ Los antecedentes de la regulación de las tasas judiciales en el Derecho español cabe situarlos en el Decreto 1053/1959, de 18 de junio, por el que se convalidó y reguló la exacción de tasas judiciales. En esta disposición se fijó un sistema de tasas cuyas cuantías venían determinadas en función de un baremo muy detallado en el que se prestaba atención al procedimiento judicial del que se tratase y a la cuantía del litigio. Esta regulación fue derogada más tarde por la Ley 25/1986, de 24 de diciembre, de Supresión de las Tasas Judiciales. Y su recuperación, calificada como «limitada», pues sólo habían de satisfacerse en los órdenes contencioso-administrativo y civil, y por las personas jurídicas o entidades sin personalidad jurídica con ánimo de lucro que promoviesen el proceso y cuya facturación viniese cifrada en varios millones de euros, tuvo lugar mediante el art. 35 de la Ley 53/2002, de 30 de diciembre, de Medidas Fiscales, Administrativas y del Orden Social. Su ampliación sustancial, con todos los problemas puestos de relieve por la doctrina, incluidos los de constitucionalidad, se produjo con la entrada en vigor de la Ley 10/2012, de la cual, pese a «matizaciones posteriores», trae causa la STC 140/2016 ahora objeto de este comentario.

${ }^{3}$ Sobre la constitucionalidad de esta previsión legal ya se manifestó, en su día, nuestro Tribunal Constitucional en su Sentencia 20/2012, de 16 de febrero (Pleno): «En todo caso, desde nuestra perspectiva, debemos poner de manifiesto que en principio no vulnera la Constitución que una norma de rango legal someta a entidades mercantiles, con un elevado volumen de facturación, al pago de unas tasas que sirven para financiar los costes generados por la actividad jurisdiccional que conlleva juzgar demandas que libremente deciden presentar ante los tribunales del orden civil para defender sus derechos e intereses legítimos» (FJ 9. ${ }^{\circ}$ ). «Una vez obtenida la conclusión, en los fundamentos jurídicos anteriores, de que es constitucional subordinar la prestación de la actividad jurisdiccional en el orden civil al abono de unas tasas judiciales por la interposición de la demanda, tal y como establece el art. 35 de la Ley 53/2002, de 30 de diciembre, carece de lógica reprochar que el legislador haya decidido que la contribución de los justiciables a la financiación de la justicia se produzca mediante tasas, cuyo previo pago es requerido como regla general para obtener el beneficio ínsito en la prestación pública y sostener que debería ser liquidado y ejecutado de un modo más adecuado a la estructura típica de los impuestos, que es lo que, en definitiva, afirma el auto de planteamiento de la cuestión. Lo que el legislador ha decidido, en términos que constitucionalmente son irreprochables, es que las sociedades de grandes dimensiones, según la legislación tributaria, sólo puedan obtener la prestación de la actividad jurisdiccional cuando presenten demandas civiles si liquidan y abonan una tasa que permite sufragar parcialmente el coste que implica para la justicia atender y resolver su demanda. La previsión legal de que, si la tasa judicial no es liquidada y abonada, la potestad jurisdiccional civil no debe ser ejercida en beneficio del sujeto pasivo, es una consecuencia ineludible de la regulación legal, que no suscita reparo de constitucionalidad. Es lícito que el legislador adopte medidas para lograr un alto grado espontáneo de la obligación de pagar un tributo legítimo, aun cuando esas medidas incidan en el ejercicio del derecho de acceso a la jurisdicción [...] la norma no carece de justificación razonable y no es contraria al principio de capacidad económica en el caso de las tasas judiciales contempladas por la presenta- 
impugnada generaliza la obligación del pago de la tasa judicial, ampliando el hecho imponible a todos los órdenes jurisdiccionales, salvo el penal, y como sujeto obligado a todas las personas físicas y jurídicas, mientras que la cuantía del tributo se eleva sin mesura ni fórmulas adecuadas de ponderación y determinación, lo que vulnera, a su juicio, el derecho de acceso a la justicia (art. 24.1 CE).

Por su parte, el segundo apartado dentro del primer motivo del recurso, titulado «La sintonía de la jurisprudencia constitucional y europea con las cautelas hasta entonces observadas por el legislador», pasa revista a los pronunciamientos efectuados tanto por el propio Tribunal Constitucional (v. gr., STC 20/2012) ${ }^{4}$ como por el TEDH en casos de exigencia por el Estado de una tasa para el acceso a la justicia (art. 6.1 CEDH) ${ }^{5}$. Con base en ellos afirman los recurrentes que gravar a las personas físicas convierte a la Ley 10/2012 en una categoría sospechosa desde la perspectiva del derecho fundamental al acceso a la jurisdicción (art. 24.1 CE) y de la garantía de la gratuidad de la justicia establecida en el art. 119 CE.

El segundo motivo del recurso de inconstitucionalidad presentado, bajo el título de «La Ley 10/2012, de 20 de noviembre, vulnera los arts. 1, 9.2, 24.1, 106 y 119 de la Constitución», se divide en tres grandes apartados: en el primero, relativo al efecto disuasorio de la Ley como factor lesivo del derecho a la tutela judicial, se sostiene que la tasa regulada por la Ley 10/2012 produce, por su extensión y cuantía, un efecto disuasorio que lesiona el derecho fundamental de acceso a la justicia; en el segundo, relativo a la evidencia de los casos concretos, se argumenta que el funcionamiento de la tasa judicial impugnada producirá dos efectos absolutamente rechazables: se va a impedir a determinados ciudadanos acceder a los tribu-

ción de demandas civiles establecidas por la Ley 53/2002» (FJ 11). «Es evidente que las tasas judiciales establecidas en la Ley 53/2002 como condición para que los tribunales del orden civil den curso a las demandas presentadas por los justiciables, en los términos que han sido examinados por esta sentencia, son tributos cuyo hecho imponible no es ajeno a la función jurisdiccional y que imponen una carga económica que persigue un fin vinculado al proceso mismo. Por consiguiente, es constitucionalmente válida la limitación impuesta por la norma legal enjuiciada, que consiste en condicionar la sustanciación del proceso instado en la demanda civil que presentan las personas jurídicas con ánimo de lucro, sujetas al impuesto de sociedades y con una facturación anual elevada, a que acrediten haber satisfecho el deber de contribuir al sostenimiento del gasto público que conlleva el ejercicio de la potestad jurisdiccional, que les beneficia de modo particular en la medida en que juzga las pretensiones deducidas en defensa de sus derechos e intereses legítimos en el orden civil» (FJ 12).

${ }^{4}$ STC 20/2012, de 16 de febrero (Pleno).

5 Para un examen exhaustivo de la jurisprudencia del Tribunal Europeo de Derechos Humanos sobre esta materia, vid., por todos, G. DOMÉNECH PASCUAL, «Las tasas judiciales a juicio...», op. cit, pp. 25 y ss. 
nales de justicia como consecuencia de la ausencia de capacidad económica para hacer frente al pago de la tasa, y resultará económicamente más gravoso acudir a los tribunales en el ámbito de determinadas reclamaciones, puesto que la cantidad necesaria va a ser superior que el propio contenido de la reclamación, y en el tercer apartado de este motivo del recurso, titulado «La vulneración del art. 47 de la Carta de Derechos Fundamentales de la Unión Europea, en relación con el art. 10 de la Constitución Española de 1978», los recurrentes afirman que se ha infringido el art. 47 de la Carta que recoge el derecho a la tutela jurisdiccional, desatendiendo de esta forma la doctrina del propio Tribunal Constitucional que, por la vía del art. 10.2 $\mathrm{CE}$, ha extendido la interpretación de los derechos fundamentales a aquellas normas de Derecho comunitario que los consagran.

El tercer motivo del recurso de inconstitucionalidad, bajo el título de «Vulneración del derecho a la igualdad del art. 14 CE», plantea la vulneración de dicho derecho como consecuencia del sistema de tasas judiciales incorporado en la Ley 10/2012. En concreto, los recurrentes sostienen que el derecho fundamental a la igualdad queda afectado tanto desde la vertiente del art. 9.2 $\mathrm{CE}$ como de la del art. $14 \mathrm{CE}$, en cuanto comporta un deber prestacional del Estado para la consecución de la igualdad material o sustancial; deber que ha quedado incumplido. Afirman que la Ley impugnada, al establecer una intensa diferencia entre los ciudadanos a la hora de acceder a los órganos jurisdiccionales, distinguiendo entre los que tienen suficiencia de recursos para hacer frente a unas elevadas tasas y los que no, infringe totalmente lo dispuesto en los arts. 14 y 9.2 de la Constitución, sin que exista para ello ninguna justificación objetiva y razonable, puesto que ni para financiar el sistema de justicia gratuita ni para financiar el sistema judicial tiene sentido la expulsión de una parte de la ciudadanía del acceso a los órganos jurisdiccionales. El recurso conecta esta censura con la inobservancia de la cláusula del Estado social y democrático de Derecho del art. 1.1 CE y el valor superior de la justicia, constituida ésta como una de las prestaciones mínimas que debe proporcionar el Estado social a sus ciudadanos. Además, desde la óptica del art. $14 \mathrm{CE}$, se aprecian por los recurrentes supuestos tanto de violaciones directas como indirectas de la igualdad.

Finalmente, el recurso de inconstitucionalidad cierra su cuarto motivo, titulado «La regulación de la tasas judiciales tampoco se ajusta al principio de capacidad económica previsto en el art. 31.1 de la Constitución», recordando que las cuantías de las tasas de la Ley 10/2012 impiden u obstaculizan de forma irrazonable, en la práctica, el ejercicio del derecho funda- 
mental a la tutela judicial efectiva, por lo que tal conjunto normativo debe ser considerado incompatible con el art. 24.1 CE. Más concretamente, se dice por los recurrentes que las tasas impugnadas producen una específica infracción del derecho a la tutela judicial efectiva, sea cual sea su alcance, en cuanto a los principios de capacidad económica y progresividad en relación a dichas tasas, pues la ley no puede desconocer que un tributo no puede impedir el ejercicio de los derechos fundamentales, ya que de ser así, tal incongruente efecto no cumpliría con las exigencias contempladas en el art. 31 CE. En consecuencia, los recurrentes acaban afirmando que la regulación impugnada por tal motivo no supera el juicio de proporcionalidad que es exigible en esta materia, con infracción de los principios de capacidad económica y progresividad, y, en definitiva, con infracción de los principios que definen el constitucional deber de contribuir, produciéndose un resultado excesivamente gravoso o desmedido en el reparto de la carga tributaria para el sostenimiento de los gastos públicos.

\section{FUNDAMENTACIÓN JURÍDICA}

Tras la toma en consideración, como es lógico, del escrito presentado por el abogado del Estado interesando la inadmisión parcial del recurso de inconstitucionalidad y la desestimación del mismo en todo lo demás por no estar acreditadas la conculcaciones constitucionales aludidas en el recurso, el Pleno del Tribunal Constitucional, en la Sentencia objeto de este comentario, termina por: a) estimar parcialmente el recurso de inconstitucionalidad formulado contra los arts. 1, 2, 3, 5, 6, 7 y 11 de la Ley 10/2012; b) declarar la pérdida sobrevenida del objeto del recurso en lo que se refiere a la impugnación del art. 3.1 y de los arts. 1 y 7 en su aplicación a las personas físicas; c) declarar la inconstitucionalidad y nulidad del art. 7.1 en los siguientes incisos: «En el orden jurisdiccional civil [...] apelación: 800 euros; casación y extraordinario por infracción procesal: 1.200 euros»; «En el orden jurisdiccional contencioso-administrativo: abreviado: 200 euros; ordinario: 350 euros; apelación: 800 euros; casación: 1.200 euros» $\mathrm{y}$ «En el orden social: suplicación: 500 euros; casación: 750 euros», con los efectos indicados en el FD 15; d) declarar la inconstitucionalidad y nulidad del art. 7.2, con los efectos indicados en el FJ 15, y e) desestimar el recurso en todo lo demás.

Sin perjuicio de la pérdida sobrevenida del objeto del recurso en lo relativo a la impugnación de los arts. 1 y 7 respecto a las personas físi- 
cas, que trae su causa de la entrada en vigor del art. 11 del Real Decretoley $1 / 2015$, de 27 de febrero, sobre mecanismos de segunda oportunidad, reducción de carga financiera y otras medidas de orden social (convalidado por Acuerdo del Congreso de los Diputados de 12 de marzo de 2015, publicado en el $B O E$, núm. 66, de 18 de marzo), y del posterior art. 10 de la Ley 25/2015, de 28 de julio, sobre mecanismos de segunda oportunidad, reducción de carga financiera y otras medidas de carácter social, así como del art. 3.1 por obra de la reforma operada por el Real Decreto-ley 3/2013, de 22 de febrero, por el que se modifica el régimen de las tasas en el ámbito de la Administración de Justicia y el sistema de asistencia jurídica gratuita (convalidado por Acuerdo del Congreso de los Diputados de 14 de marzo de 2013, publicado en el BOE, núm. 69, de 21 mazo), el resto de fundamentos jurídicos de la Sentencia objeto de este comentario se centran en analizar la posible inconstitucionalidad de diferentes preceptos de la Ley 10/2012.

Así, en primer lugar, en su fundamento jurídico $3 .^{\circ}$ se analiza el art. 1 de la Ley 10/2012, referido al ámbito de aplicación de la tasa por el ejercicio de la potestad jurisdiccional en los órdenes civil, contencioso-administrativo y social: «La tasa por el ejercicio de la potestad jurisdiccional en los órdenes civil, contencioso-administrativo y social tiene carácter estatal y será exigible por igual en todo el territorio nacional en los supuestos previstos en esta Ley, sin perjuicio de las tasas y demás tributos que puedan exigir las Comunidades Autónomas en el ejercicio de sus respectivas competencias financieras, los cuales no podrán gravar los mismos hechos imponibles».

En relación a este precepto, el TC señala que, dado que los recurrentes sostienen que es inconstitucional pagar una tasa para el acceso a la justicia (art. 24.1 CE), en su doble vertiente de acceso a la jurisdicción y de acceso al recurso, en los órdenes contencioso-administrativo y social, la queja debe ser respondida partiendo del contenido y límites del derecho previsto en el art. 119 CE, a cuyo tenor: «La justicia será gratuita cuando así lo disponga la ley y, en todo caso, respecto de quienes acrediten insuficiencia de recursos para litigar». Nuestro máximo intérprete constitucional termina por concluir en este punto que si la conculcación constitucional de la que alertan los recurrentes en su demanda deriva propiamente no del mero hecho de la imposición de la tasa, sino del eventual carácter excesivo de cuantía, vinculada al valor económico del litigio, así como que tal aspecto no afecta, en verdad, a la constitucionalidad del art. 1 de la Ley 10/2012, sino, en su caso, a la del art. 7 de la Ley, parece lógico estimar, sin perjuicio de lo que 
proceda ponderar en relación al art. 7, que el contenido propio del art. 1 de la Ley 10/2012 es ajustado a las exigencias de constitucionalidad.

Por su parte, en el fundamento jurídico $4 .^{\circ}$ nuestro TC afronta el análisis acerca de la posible inconstitucionalidad del art. 7 de la Ley 10/2012, referido a la determinación de la cuota tributaria: «1. Sin perjuicio de su modificación en la forma prevista en el art. 8, será exigible la cantidad fija que, en función de cada clase de proceso, se determina en la siguiente tabla. En el orden jurisdiccional civil: verbal y cambiario: 150 euros; ordinario: 300 euros; monitorio, monitorio europeo y demanda incidental en proceso concursal: 100 euros; ejecución extrajudicial y oposición a la ejecución de títulos judiciales: 200 euros; concurso necesario: 200 euros; apelación: 800 euros; casación y extraordinario por infracción procesal: 1.200 euros. Cuando después de la oposición del deudor en un monitorio se siga un proceso ordinario se descontará de la tasa la cantidad ya abonada en el proceso monitorio. En el orden jurisdiccional contencioso-administrativo: abreviado: 200 euros; ordinario: 350 euros; apelación: 800 euros; casación: 1.200 euros. En el orden social: suplicación: 500 euros; casación: 750 euros. 2. Deberá sustanciarse, además, la cantidad que resulte de aplicar a la base imponible determinada con arreglo a lo dispuesto en el artículo anterior el tipo de gravamen que corresponda, según la siguiente escala: de 0 a 1.000.000 euros: tipo 0,5 por 100; resto: tipo 0,25 por 100; máximo variable: 10.000 euros».

Este motivo impugnatorio se bifurca en dos direcciones: según la primera, se sostiene que la Ley 10/2012 no tiene en cuenta la situación de aquellos que carecen de «capacidad económica» (suficiencia de recursos) para satisfacer la tasa, lo que trae consigo la imposibilidad de ejercicio del derecho a la tutela judicial efectiva en tales supuestos, añadiendo en este punto que ni para financiar el sistema de justicia gratuita ni para financiar el sistema judicial tiene sentido la expulsión de una parte de la ciudadanía del acceso a los tribunales de justicia (a ello se opuso el abogado del Estado afirmando que se trataría de casos excepcionales, lo que no puede servir de criterio para medir la constitucionalidad de la norma), y, en atención a la segunda, se sostiene también por los recurrentes que las desproporcionadas cuantías de la tasa judicial (cuota fija y cuota variable con sus escalas) producen, en última instancia, un efecto disuasorio o inhibidor para impetrar el auxilio de los órganos jurisdiccionales (el abogado del Estado niega dicha desproporcionalidad, recordando que una cuota similar para el acceso al orden contencioso-administrativo ya se preveía en el art. 35 de la Ley 53/2002, que mayor carga económica comporta la asunción de 
los gastos de abogado y procurador frente a los de la tasa, y que el sistema favorece que paguen la tasa quienes ejercitan pretensiones bien fundadas, al tiempo que propicia que la Administración reconozca ésta en vía administrativa o, en su caso, se allane a la demanda para evitar su condena en costas).

En relación al problema de la insuficiencia económica del obligado al pago de la tasa judicial, el propio TC viene afirmando que si bien el derecho de acceso a la jurisdicción, vertiente de aquel más general a la tutela judicial efectiva (art. 24.1 CE), es un derecho fundamental de configuración legal que, en virtud de este último carácter, conlleva un grado de libertad de actuación del legislador para definir las condiciones y requisitos determinantes de dicho acceso en los distintos órdenes, no lo es menos que esta tarea de configuración tampoco está exenta de limitaciones. De hecho, como así puede apreciarse con la lectura del fundamento jurídico $6 .^{\circ}$ de la Sentencia objeto de este comentario, lo que en realidad cabe verificar es hasta qué punto las medidas de protección de las personas jurídicas (únicas sobre las que cabe pronunciarse según nuestro máximo intérprete constitucional, una vez ya declarada la pérdida parcial de objeto del recurso de inconstitucionalidad en relación a las personas físicas) exigidas por nuestra doctrina y por la jurisprudencia del TEDH quedan debidamente garantizadas por la Ley 10/2012, directamente en su texto o por remisión a otras leyes. En consonancia con todos los supuestos de exención y de pago flexible de la tasa judicial a las que pueden acogerse las personas jurídicas, nuestro TC termina por concluir que su art. 7 no conculca el derecho de acceso (a la jurisdicción o al recurso) del art. 24 CE, en virtud de una supuesta desprotección ante situaciones de insuficiencia económica del obligado a su pago.

La segunda queja vertida por los recurrentes respecto a la vulneración del derecho de acceso del art. 24.1 CE dentro de la órbita del art. 7 de la Ley 10/2012 viene referida a que la tasa en cuestión se traduce en una barrera económica que, de forma desproporcionada, termina por inhibir o disuadir a muchos ciudadanos de ejercitar su derecho fundamental en el orden contencioso-administrativo, cuando se trata de reclamaciones de pequeña o escasa cuantía, o bien de impugnar la legalidad de disposiciones generales y contra las vías de hecho, cuando se trata de demandas de importe elevado. De igual forma, también se afirma por los recurrentes que resulta disuasoria la tasa fijada para los recursos.

Este queja debe analizarse desde el prisma de la «proporcionalidad». En esta línea, nuestro Tribunal Constitucional acepta que uno de los 
fines limitativos del derecho de acceso tanto a la jurisdicción como al recurso sea el de la prevención o disuasión de comportamientos abusivos en su ejercicio. Por ende, concluye que resulta legítimo constitucionalmente en relación con la Ley impugnada. De forma paralela, nuestro TC considera que el objetivo de la financiación mixta de la justicia a cargo de las tasas judiciales, si bien es en sí mismo legítimo, lo cierto es que no deviene prioritario ni puede traer consigo, mediante la implantación de tasa excesivas, la imposibilidad de ejercicio de un derecho fundamental (art. 24.1 CE), con la consiguiente inacción de la propia función atribuida a los juzgados y tribunales. Por ello, precisamente, la respuesta a la queja formulada por los recurrentes solo puede enfrentarse en atención a la ponderación de la proporcionalidad de lo contemplado expresamente en la Ley 10/2012.

Nuestro máximo centinela constitucional, tras estimar que la tasa aquí impugnada se muestra como idónea para alcanzar el fin constitucionalmente legítimo de mantener un modelo de financiación mixta de la justicia, termina por concluir que dicha tasa, sin embargo, no reúne la idoneidad necesaria para aquel otro fin trazado por la Ley 10/2012 (en sí mismo también legítimo), como es el de disuadir de la interposición abusiva de recursos. De ahí, precisamente, que el examen acerca de la constitucionalidad de las previsiones de su art. 7 deba abordarse desde una perspectiva recaudatoria, única desde la que cabe verificar si concurren, en el presente caso, los atributos de necesidad y proporcionalidad en sentido estricto.

En lo que concierne a la «necesidad» de la medida, ésta no ofrece dificultad alguna de comprensión bajo el parámetro de valoración expuesto en las líneas precedentes. En efecto, una vez que el legislador ha asumido, dentro del margen de libertad del que dispone, que un porcentaje de los gastos que se derivan del funcionamiento de la justicia deban ser sufragados por quienes precisamente promueven la actuación de los órganos judiciales, aunque siga siendo mayoritaria la aportación del conjunto de los contribuyentes por la vía de los impuestos, no cabe cuestionar, en momento alguno, la elección de la tasa impugnada como instrumento recaudatorio, y ni siquiera los recurrentes niegan en sí misma la validez de este sistema de financiación mixta de la justicia.

Mayores problemas se plantean desde la óptica de analizar la proporcionalidad o no de las tasas que han sido objeto de impugnación, en el sentido de verificar si provocan que quienes disponen de medios económicos suficientes para afrontar su pago dejan, sin embargo, en la práctica, de ejercitar la acción o el recurso que tenían por ley a su alcance, dado el 
valor económico del objeto controvertido puesto en relación con el importe de la tasa en cuestión.

Respecto a la fijación de una tasa para el acceso a la jurisdicción, el TC constata en la fundamentación jurídica de la sentencia objeto de este comentario, que la exposición de motivos de la Ley 10/2012 no contiene referencia alguna a los criterios que han llevado a la asignación de los importes de las respectivas cuotas. Por su parte, la Memoria de Análisis del Impacto Normativo del entonces Proyecto de Ley estimaba unos ingresos en el primer año de entrada en vigor de 306.091.358,50 euros, mientras que la suma presupuestada para el funcionamiento total de los juzgados y tribunales ascendía, ya en 2011, a 1.313.848.180 euros, esto es, una suma más de cuatro veces superior. Lo expuesto, sin embargo, a juicio de nuestro TC, no es suficiente para resolver el problema acerca del respeto o no de la proporcionalidad en sentido estricto. A tal fin resulta obligado, en consecuencia, referirse a cada uno de los módulos que contempla la norma para el cálculo de la cuota a pagar: la cantidad fija y la cantidad variable.

En cuanto a la cuota fija, como puede leerse en el fundamento jurídico 11 de la Sentencia comentada, la demanda sostiene que la imposición de la tasa en sus importes bien pudiera comportar una medida de efectos inhibidores y disuasorios, y, por ello, injustificadamente desproporcionados, en los siguientes ámbitos de tutela jurisdiccional donde su pago se muestra como especialmente gravoso: a) las demandas de pequeña cuantía en el orden contencioso-administrativo, y b) la interposición de recursos (segunda instancia y recursos extraordinarios) en los tres órdenes jurisdiccionales donde la misma es exigible.

Nuestro TC concluye, tras analizar los argumentos expuestos en su escrito por el abogado del Estado, que la tasa de 200 euros para la interposición del recurso contencioso-administrativo abreviado, como la de 350 euros para la interposición del recurso contencioso-administrativo ordinario, ambas previstas para las personas jurídicas en el art. 7.1 de la Ley 10/2012, resultan desproporcionadas y, por ello, contrarias al acceso a la jurisdicción (art. 24.1 CE). Y a ello añade nuestro máximo intérprete constitucional, lo cual no compartimos y así lo desarrollaremos en el siguiente apartado de este comentario, que la demanda no formuló cuestión alguna acerca de la cuota establecida en el art. 7.1 de la Ley 10/2012 para los procesos civiles en primera o única instancia [recordando, además, en este punto que el art. 4.1.c) declara exentos del pago de la tasa a los procesos civiles por reclamación de cantidad hasta los 2.000 euros, salvo cuando se trate de la ejecución de títulos extrajudiciales]. En cuanto al segundo supuesto 
de efectos disuasorios o inhibidores de la tasa fija de la Ley 10/2012, relativo a la interposición de recursos contra sentencias, nuestro TC no aprecia razón o justificación alguna que acredite que se haya tenido en cuenta que las cuantías establecidas en el art. 7 de la Ley 10/2012, para la interposición de recursos, se adecuen a la capacidad económica que no exceda de la que pueda poseer una persona jurídica, razón por la cual se concluye que dichas tasas son contrarias al obligado respeto del art. 24.1 CE.

En orden a la hipotética falta de proporcionalidad de la cuota variable, tratada en concreto en el fundamento jurídico 13 de la sentencia objeto de este comentario, tanto para procesos en primera o única instancia como respecto de la interposición de los recursos (art. 7.2 de la Ley 10/2012) y referida, tras la pérdida parcial del objeto del recurso, a las personas jurídicas, nuestro TC ha estimado, sin llegar a entrar a valorar los porcentajes y límite de la escala variable, que resulta inconstitucional por infracción del derecho fundamental de acceso a la jurisdicción y el recurso (art. 24.1 CE). Dicha cuota variable supone recaudar una segunda cantidad en función de un porcentaje determinado sobre el valor económico del litigio, siempre que sea calculable dicho valor conforme a las reglas de procedimiento y, de no ser así, aplicando a estos efectos un valor ficticio de 18.000 euros, conforme determinaba previamente el art. 6.2 de la propia Ley 10/2012. Así regulada esta cuota variable, lo cierto es que eleva, innecesariamente, la carga económica de la entidad actora o recurrente en todos los grados de la jurisdicción en los que se satisface su pago, sin que sea posible discernir a qué criterio responde su exigencia, pues la Memoria del Análisis de Impacto Normativo nada nos aclara sobre este particular. Si se trata de presumir como riqueza patrimonial, la mera solicitud de tutela judicial no puede estimarse un parámetro objetivamente adecuado. Y tampoco lo es entender, pues no es así, que el criterio del valor del litigio guarda relación con el coste del ejercicio de la función jurisdiccional, máxime si tenemos presente, además, que las desigualdades se producen en un mismo tipo de procedimiento.

Siendo esto así, nuestro TC ha concluido, en este punto, que en nuestro Estado Social y Democrático de Derecho, el cual propugna entre otros valores superiores, los relativos a la Justicia y la Igualdad (art. 1.1 CE), lo cierto es que el pago de un tributo no puede terminar por obstaculizar el ejercicio de un derecho fundamental.

Llegados a este punto, resulta obligado señalar que el recurso de inconstitucionalidad sostiene, como última queja, que el importe excesivo de las tasas infringe no sólo el derecho a la tutela judicial efectiva (derecho de acceso) sino también los principios tributarios de capacidad económi- 
ca y progresividad consagrados en el art. 31 CE. Así planteada la cuestión en orden a las tasas del art. 7 de la Ley 10/2012, nuestro máximo intérprete constitucional no se pronuncia, pues dichas tasas, con carácter previo, en los Fundamentos de Derecho precedentes, ya fueron declaradas inconstitucionales y nulas por vulneración del derecho a la tutela judicial efectiva (art. 24.1 CE).

Igualmente, no podemos dejar de tomar en consideración el fundamento jurídico 15 de la Sentencia del Tribunal Constitucional objeto de este análisis, pues en el mismo se precisa el alcance que se deriva, en la práctica, de las declaraciones de inconstitucionalidad que han sido acogidas en relación a diferentes preceptos de la Ley 10/2012. En primer lugar, se nos dice que la declaración de inconstitucionalidad supone la nulidad del apartado 1 del art. 7 de la Ley en los distintos incisos que prevén, de manera separada, las cuotas fijas siguientes, en este caso a las personas jurídicas: «La de 200 euros para interponer el recurso contencioso-administrativo abreviado y la de 350 euros para interponer el recurso contencioso-administrativo ordinario; la de 800 euros para promover recurso de apelación y la de 1.200 euros para los recursos de casación y extraordinario por infracción procesal en el orden civil; la de 800 euros para el recurso de apelación y la de 1.200 euros para el recurso de casación en cualquiera de sus modalidades en el orden contencioso-administrativo; así como también la nulidad de la tasa de 500 euros para el recurso de suplicación y 750 para el de casación en cualquiera de sus modalidades en el orden social». También se declara la nulidad de la cuota variable para las personas jurídicas recogida en el apartado 2 del art. 7 de la Ley 10/2012.

Por último, respecto de ambos pronunciamientos de nulidad, se concreta por nuestro TC que resulta de aplicación la doctrina reiterada en atención a la cual: «En supuestos como el que ahora nos ocupa y atendiendo a la pluralidad de valores constitucionales que concurren, debemos traer a colación, a la hora de precisar el alcance en el tiempo de la declaración de nulidad, el principio de seguridad jurídica (art. 9.3 CE), según el cual las sentencias declaratorias de la inconstitucionalidad de leyes no permitirán revisar procesos ya fenecidos mediante sentencia con fuerza de cosa juzgada». A ello añade también nuestro TC que «el principio de seguridad jurídica (art. 9.3 CE) también reclama — que es el asunto que nos ocupa- que la declaración de inconstitucionalidad sólo sea eficaz pro futuro, esto es, en relación con nuevos supuestos o con los procedimientos administrativos y procesos judiciales donde todavía no haya recaído una resolución firme». Y se concluye, en particular, «que no procede orde- 
nar la devolución de las cantidades pagadas por los justiciables en relación con las tasas declaradas nulas, tanto en los procedimientos administrativos y judiciales finalizados por resolución ya firme como en aquellos procesos aún no finalizados en los que la persona obligada al pago de la tasa la satisfizo sin impugnarla por impedirle el acceso a la jurisdicción o al recurso en su caso, deviniendo con ello firme la liquidación del tributo».

III. ALGUNAS REFLEXIONES ACERCA DE LA STC 140/2016, DE 21 DE JULIO, EN LA QUE SE EXAMINAN

DETERMINADOS PRECEPTOS DE LA LEY 10/2012, DE 20 DE NOVIEMBRE, POR LA QUE SE REGULAN DETERMINADAS TASAS EN EL ÁMBITO DE LA ADMINISTRACIÓN DE JUSTICIA Y DEL INSTITUTO NACIONAL DE TOXICOLOGÍA Y CIENCIAS FORENSES

La STC 140/2016, que no ha escapado a importantes críticas de un sector doctrinal por desconocer o no ponderar que en la mayoría de países europeos existen tasas judiciales de cuantías muy superiores a las previstas en la Ley 10/2012, por no conocer en su integridad la jurisprudencia del TEDH o por utilizar un criterio especialmente restrictivo en orden a evaluar su proporcionalidad ${ }^{6}$, así como de otro sector de la doctrina por todo lo contrario, esto es, por haber sido dictada con un claro efecto de contención de sus efectos, en el sentido de afirmar, por ejemplo, en su fundamento jurídico 11, que no se ha formulado ninguna cuestión sobre la cuota fija establecida en el art. 7.1 de la Ley impugnada por lo que hace referencia a los procesos civiles en primera o única instancia, lo cual impide al TC pronunciarse sobre esta cuestión (cuando lo cierto es que si se analiza el contenido del texto del recurso cabe apreciar, lo que bien podría constituir una «incongruencia por omisión», que el vicio de inconstitucionalidad no es imputado, en exclusiva y de forma aislada, a preceptos concretos de la Ley 10/2012, sino a su efecto «combinado», pues toda ella configura un sistema legal cerrado de recaudación tributaria que limita de forma irrazonable y discriminatoria el ejercicio de los derechos fundamentales e incorpora soluciones contrarias a los principios básicos del texto constitucional;

${ }^{6}$ En este punto vid., por todas, las reflexiones apuntadas por G. DOMÉNECH PASCUAL, «Proporcionalidad marca España: las tasas judiciales y el Tribunal Constitucional», Agenda Pública, Analistas de la Actualidad, 17 de octubre de 2016, pp. 1 y ss., e íD., «Las tasas judiciales a juicio...», op. cit., pp. 32 y ss., y, a modo de conclusión, en especial p. 50. 
que uno de los preceptos impugnados es, precisamente, el art. 7.1 de Ley, y, finalmente, que todo ello implica una vulneración del llamado principio de capacidad económica en materia tributaria, principio éste de carácter general y, en consecuencia, vinculado con todos los órdenes jurisdiccionales — también el civil —-), ha declarado inconstitucional y anulado la tasa judicial estatal prevista en la Ley 10/2012 para el ejercicio de la potestad jurisdiccional en el orden contencioso-administrativo, en el orden social y en el orden civil (si bien, en este último supuesto, se mantienen para la primera instancia las cuotas tributarias fijas).

En atención a esta sentencia de nuestro Tribunal Constitucional, ahora objeto de comentario, lo inconstitucional no lo es la tasa en sí misma considerada, sino su cuantía. De hecho, nuestro Tribunal Constitucional ha precisado que, en principio, el establecimiento de tasas para el ejercicio de acciones judiciales en los órdenes civil, contencioso-administrativo y social no supone vulneración alguna del derecho fundamental a la tutela judicial efectiva (art. 24.1 CE), así como tampoco del art. 119 CE, siempre, eso sí, que se contemplen diferentes supuestos de exclusión y de pago flexible para aquellas personas jurídicas que no cuenten con suficientes recursos para litigar. Por el contrario, en atención a su desproporción y posible efecto disuasorio, lo que nuestro máximo intérprete constitucional ha reputado como inconstitucional es su elevada cuantía. En consecuencia, según esta jurisprudencia, dado que la inconstitucionalidad viene referida al carácter excesivo de la cuantía de la tasa, nada obsta al legislador ordinario para establecer un sistema de tasas (también llamado de «copago») respetuoso con el derecho a la tutela judicial efectiva.

En este punto, aun cuando en teoría seríamos partidarios de un sistema total de gratuidad de la justicia propio del Estado del bienestar, que bien podría venir amparado, diga lo que diga nuestro TC, por la dicción literal del art. $119 \mathrm{CE}^{8}$, lo cierto es que, como también puede apreciarse en los países de nuestro entorno, máxime en una situación de crisis económica (no ya coyuntural, sino estructural), parece aceptable, aunque no sea un ideal, el abogar por la aplicación, en cuanto a la financiación de la Administración de Justicia, del llamado principio de justicia distribu-

${ }^{7}$ En esta línea interpretativa vid., por todos, I. GARCÍA, «Algunes reflexions critiques a la llum de la Sentència 140/2016 del Tribunal Constitucional: De nou, sobre les taxes judicials», Món Jurídic, Revista de l'Illustre Colllegi d'Advocats de Barcelona, núm. 308 (2016), pp. 8 y 9 .

8 Así se ha manifestado, con claridad meridiana, J. M. Asencio Mellado, «La inconstitucionalidad de la Ley...», op. cit, pp. 3 y ss. 
tiva, en el que tienen cabida las costas y las tasas, y el cual, como es lógico, debe acompañarse, en todo caso, de un adecuado sistema de asistencia jurídica gratuita?

Si bien la doctrina emanada de la sentencia objeto de comentario tiene validez general, es lo cierto que las tasas afectadas son sólo las relativas a las personas jurídicas, pues normativa precedente ya había eximido de dichas tasas a las personas físicas. Las tasas ya no son exigibles desde el día 15 de agosto de 2016, esto es, la fecha de publicación en el BOE de la Sentencia del Tribunal Constitucional 140/2016.

En concreto, las cuotas anuladas por la inconstitucionalidad del art. 7.1 de la Ley 10/2012 son la de 200 euros para interponer el recurso contencioso-administrativo abreviado y la de 350 euros para interponer el recurso contencioso-administrativo ordinario; la de 800 euros para promover el recurso de apelación y la de 1.200 euros para los de casación y extraordinario por infracción procesal en el orden civil, y la de 800 euros para el recurso de apelación y la de 1.200 euros para el recurso de casación en cualquiera de sus modalidades en el orden administrativo; así como la de 500 euros para el recurso de suplicación y la de 750 euros para el de casación en cualquiera de sus modalidades en el ámbito social. También ha sido declarado inconstitucional el art. 7.2 de la Ley 10/2012, relativo a la imposición de una cuota variable.

Sin embargo, no se ha producido la anulación de las tasas fijas en orden a la interposición de demanda en los procesos declarativos ordinarios. De hecho, como se ha dicho, el propio fundamento jurídico 11 de la Sentencia objeto de este comentario nos dice, textualmente y tergiversando la realidad, que, dado que la demanda no formula cuestión alguna sobre la cuota fija establecida en el art. 7.1 de la Ley 10/2012 para los procesos civiles en primera o única instancia, no le corresponde pronunciarse sobre ello. Cabe tener presente también que nuestro TC no se ha pronunciado sobre la validez constitucional de los arts. 2, 5, 6 y 11 del texto legal objeto del recurso de inconstitucionalidad del cual la sentencia analizada trae causa.

Especialmente criticable es, a nuestro juicio, que el fundamento jurídico 15 de la STC 140/2016, a la hora de modular los efectos en cuanto a la no devolución de la recaudación de la tasa en los supuestos declarados nulos por la sentencia de referencia, no solo haga mención de los pro-

\footnotetext{
${ }^{9}$ Sobre el derecho de acceso a la justicia y sus dificultades actuales, muchas de ellas derivadas de las desigualdades económicas entre los ciudadanos, vid. las reflexiones apuntadas por D. VAlLeSPín PÉREZ, Los nuevos retos del derecho a la tutela judicial efectiva en el proceso civil, Barcelona, Cims, 2009, pp. 35 y ss.
} 
cesos finalizados por sentencia firme, sino también de aquellos otros todavía no acabados, pero en los que la persona obligada al pago de la tasa ya la ha satisfecho sin haberla impugnado por impedirlo el acceso a la jurisdicción o al recurso. Esta conclusión parece no sólo poco razonable, sino también ciertamente injusta, pues no conviene olvidar, en este sentido, los efectos que derivan de la aplicación del art. 8.2 de la Ley 10/2012, que no son otros que aquellos propios de la preclusión del acto procesal y el archivo del procedimiento para aquellos casos en los que no se aporte al órgano jurisdiccional el justificante del pago de la tasa ${ }^{10}$.

La STC 140/2016 tampoco entra a analizar qué sucederá en aquellos casos en los que alguna Comunidad Autónoma haya desarrollado una normativa relativa a la fijación y pago de una tasa judicial «autonómica». Así, por ejemplo, la Comunidad Autónoma de Catalunya estableció su propia tasa judicial, la cual entró en vigor el 14 de octubre de 2014, esto es, un día después de la publicación de la Orden JUS303/2014, de 13 de octubre, por la que se estableció el procedimiento y los plazos de autoliquidación de la tasa por la prestación de servicios personales y materiales en el ámbito de la Administración de Justicia en los supuestos a que hace referencia el apartado 1 del art. 3 bis.1.1 del Texto Refundido de la Ley de Tasas y Precios Públicos de la Generalitat de Catalunya, aprobado por el Decreto Legislativo 3/2008, de 25 de junio (modificado por el Decretoley $1 / 2014$, de 3 de junio).

Este Decreto-ley de 2014 mantiene la tasa por prestación de servicios personales y materiales en el ámbito de la Administración de Justicia de competencia de la Generalitat de Catalunya, a instancia de parte, en los órdenes jurisdiccionales civil y contencioso-administrativo, en órganos judiciales con sede en la Comunidad Autónoma de Catalunya. Esta tasa catalana, que no afecta a las personas físicas ni a los autónomos ni a las PYMES y que es exigible en el ámbito civil y el contencioso-administrativo, con exclusión de los órdenes penal y social, así como de todas aquellas personas jurídicas con derecho a la asistencia jurídica gratuita, oscila entre un mínimo de 60 euros y un máximo de 120 euros.

Señalar, por último, que si bien nuestro Tribunal Constitucional, en su Sentencia 71/2014, de 6 de mayo, ha confirmado la constitucionalidad de la tasa catalana de referencia ${ }^{11}$, lo cierto es que estamos en presen-

10 I. GARCÍA, «Algunes reflexions critiques...», op. cit, p. 9.

${ }^{11}$ STC 71/2014, de 6 de mayo (Pleno): «A diferencia de lo que sucede con la tasa del Estado, la autonómica no está enlazada con el acceso a la jurisdicción o a los recursos, ya que el pago de la misma no constituye condición de admisibilidad de los actos procesa- 
cia de una tasa que no solo afecta a la primera instancia de la jurisdicción civil (como acontece con la tasa estatal), sino también a la segunda instancia civil y a las dos instancias de la jurisdicción contencioso-administrativa, lo cual ha llevado a un sector de la doctrina, no sin razón y con una cierta dosis de crítica, a defender la conveniencia de abrir una reflexión acerca de su mantenimiento en la forma descrita ${ }^{12}$.

les cuya vertiente administrativa pretende financiar [...] Mientras que la conexión de las tasas estatales con la potestad jurisdiccional es directa y resulta patente, toda vez que su impago lleva ineludiblemente aparejada la inadmisión del acto procesal al que la misma se anuda, siendo así conditio sine qua non para el propio ejercicio de la tutela judicial efectiva, el abono de la tasa autonómica carece, como no puede ser constitucionalmente de otro modo, de toda consecuencia impeditiva o retardataria del acceso a la jurisdicción. Ambas tasas resultan así compatibles desde la perspectiva de la que se ha solicitado su enjuiciamiento, toda vez que no corresponde a este Tribunal en este proceso determinar cuál haya de ser la forma más idónea de convivencia entre las tasas estatal y autonómicas, sino únicamente concluir si la tasa impugnada ha sido establecida dentro del marco competencial que a la Generalitat de Catalunya le corresponde [...] Se evidencia así que la tasa autonómica constituye el exacto reverso de la tasa estatal, recayendo la primera sobre lo que hemos denominado "vertiente puramente administrativa al servicio de la función jurisdiccional del Estado"» (FJ 5. ${ }^{\circ}$.

${ }^{12}$ I. GARCíA, «Algunes reflexions critiques...», op. cit, p. 9. 